$\begin{array}{ll}\begin{array}{l}\text { Danger signs } \\ \text { New data show } \\ \text { growing spread of } \\ \text { coral bleaching } \\ p 932\end{array} & \begin{array}{l}\text { lcy reception } \\ \text { Astronomers protest } \\ \text { over delay to Pluto } \\ \text { mission } \\ p 933\end{array}\end{array}$

\title{
NSF calls for funding boost in a bid to reverse decline in maths
}

Paul Smaglik, Washington

The US National Science Foundation (NSF) needs to more than triple its commitment to mathematics over the coming years to reverse the subject's decline and meet the growing needs of other disciplines, Rita Colwell, the director of the agency, told the National Science Board last week.

Boosting the agency's maths budget from $\$ 106$ million in 2000 to between $\$ 400$ million and $\$ 500$ million by 2007 would fund a campaign to make mathematics a more attractive profession, she said.

The proposal is expected to be a central part of the agency's next funding bid to Congress. It comes at a time when fewer graduate students are studying maths and the supply of foreign mathematicians is drying up. progress of a number of NSF initiatives, such as those in nanotechnology, biocomplexity and information technology. A lack of mathematicians could also delay analysis of the genomic and proteomic data emerging from
The resulting shortage threatens the

sequencing and related programmes.

Mathematics "underpins" all these efforts, Colwell told the National Science Board, which is formally responsible for the NSF's activities. But, she added, the discipline is being undermined by a lack of funding.

The average mathematics grant is now $\$ 30,000$ a year for three years. Colwell wants to extend this to five years and to increase the award's size - although she declined to give a figure. Without extra support, she warns, prospective mathematicians will move to other disciplines. The initiative would also provide more money for interdisciplinary research, and for training and education.

Robert Richardson, vice-provost for research and professor of physics at Cornell University, Ithaca, New York, and a member of the science board, agreed. He said that the "miserable grant size" of NSF mathematics awards deters people from following the subject at graduate level.

According to Philippe Tondeur, head of the NSF mathematics directorate and a

\section{Four more moons for Saturn}

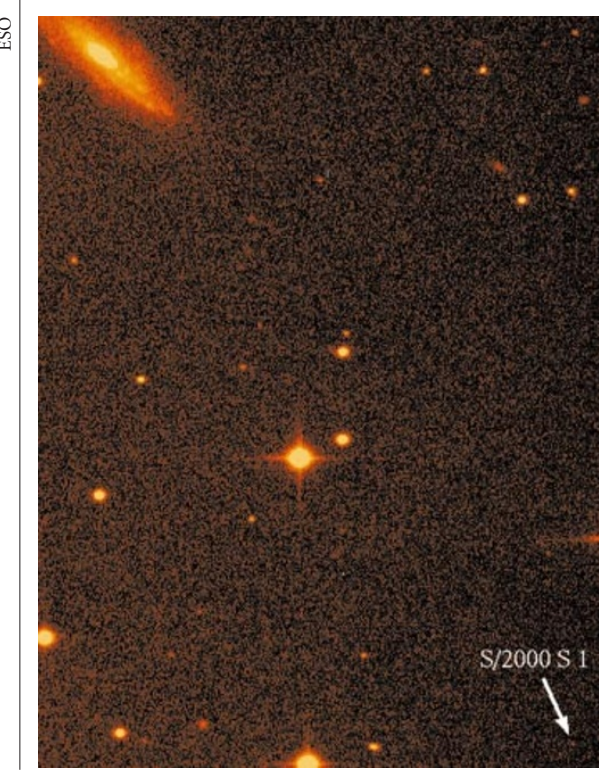

NATURE $\mid$ VOL 407 |26 OCTOBER 2000| www.nature.com

\section{David Adam}

Saturn's extended family has grown larger. Astronomers have found four more moons orbiting the planet, taking its total to 22 .

The moons are irregular and in orbits about 15 million kilometres from Saturn much further than its regular moons (see left). Their discovery puts Saturn back in the lead as the planet with the most satellites.

The moons were spotted during the past two months by several telescopes. They were due to be announced at this week's meeting of the American Astronomical Society's Division for Planetary Science in Pasadena, California.

Brett Gladman, an astronomer at the Observatoire de la Côte d'Azur, France, first noticed two of the objects in images from the European Southern Observatory's 2.2-metre telescope in Chile. The others were found using a larger instrument in Hawaii.

http://pinks.physics.mcmaster.ca/Saturn

^ิ 2000 Macmillan Magazines Ltd

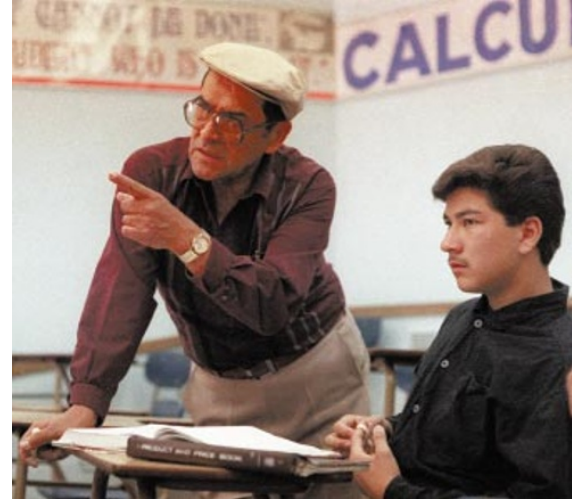

The way ahead: teaching needs more support.

maths professor at the University of Illinois at Urbana-Champaign, many undergraduates prefer to move into lucrative jobs in computer programming. Low stipends and inadequate grant support put them off a graduate education in mathematics, he says.

The proportion of US citizens among full-time maths graduate students in the United States dropped by $26.5 \%$ between 1992 and 1999 at the nation's top universities, according to figures from the American Mathematical Society.

Until recently, the United States had compensated for such shortages by bringing in mathematicians from China and Russia, just as previous shortages had been relieved by recruiting from Europe. But Tondeur says that many Chinese mathematicians are returning to their native country, and the Russian pool of talent is drying up - especially as the country's maths and science infrastructure crumbles.

Samuel Rankin, associate executive director of the American Mathematical Society, says the extra money proposed by the NSF will be good news - if it happens. "The mathematical community has to use Dr Colwell's statement and sentiment to help leverage this kind of increase for mathematics," he says.

Colwell also wants to raise the NSF stipends for graduate students from $\$ 16,800$ to $\$ 25,000$. To accomplish this while accommodating the NSF's many new and proposed initiatives, the agency will almost certainly need to double its budget over five years. 